\title{
Legados autoritários: uma leitura da formação histórico-gengráfica do Brasil contemporâneo
}

\section{Authoritarian legacy: a reading of the historical and geographical formation of contemporary Brazil}

\section{Resumo:}

Este artigo propõe compreender de maneira inconclusa e circunstancial o Brasil contemporâneo, seus legados e processos de formação histórico-geográficos. Uma busca de entendimento acerca da sua formação como processo autoritário e as prevalências de tais raízes nas relações socioespaciais encontradas até os dias de hoje. Nesse sentido, o termo autoritário é utilizado de forma ampla, abarcando desde o período colonial até os processos de democratização mais recentes.
* Geógrafa e Mestre em Geografia pela Universidade Federal de Minas Gerais (UFMG). Professora do Núcleo de Geografia do Centro Pedagógico da UFMG.

\section{Abstract:}

This paper proposes understand inconclusive and circumstantial way contemporary Brazil, its legacy and processes of historical and geographical formation. A search of understanding about your make up as authoritarian process and the prevalence it in the socio-spatial relationships found to this day. In this sense, the authoritarian term is used broadly, encompassing from the colonial period to the most recent democratization processes.

\section{Palavras-chave:}

estado-nação, autoritarismo, Brasil, resistência, utopia

Key-Words: nation-state, authoritarianism, Brazil, resistance, utopia 
INTRODUÇÃO

$\mathbf{B}_{\text {do sob massacres, desigualdades e expro- }}^{\text {rasil, uma invenc̃a brutal. País demarca- }}$ priações. Legados repletos de violentos confrontos e desmandos. Pensar e viver o Brasil, hoje, é experiencia-lo a partir de raízes autoritárias e suas prevalências. Tais experiências coexistem com movimentos de resistências e com resignações.

Partir do Brasil como leitura da formação violenta de um país é uma estratégia tanto de contextualização quanto de entendimento de um significativo processo histórico, circunstancial. Pensá-lo desta forma permite pensar limitações e possibilidades, heranças e utopias. "O Brasil foi 'inventado' de cima para baixo, autoritariamente" (FREIRE, 1991, p. 35). Compreendê-lo como uma sociedade autoritária é dizer que nele gestou-se uma estrutura marcada por profundas desigualdades. É assumir que desde sua invenção a grande maioria de suas gentes-habitantes não foi devidamente considerada nos seus desenhos de percursos.

Não é difícil, sem que se esmiúce a história do Brasil, exemplificar o autoritarismo desde sua fundação como colônia até a contemporaneidade. Contudo, este não é um artigo historiográfico. Por isso, intencionam-se breves problematizações de Brasis autoritários. Apenas passagens, acontecimentos que auxiliem tais entendimentos acerca desses processos de formação.

A intenção é a de tentar perceber insistências autoritárias em vários momentos vividos e experienciados pelas gentes-habitantes do Brasil. E, para além disso, apreender, entrelaçados a eles, movimentos de resistências e transgressões - não raramente invisibilizados ou desvalorizados. Estes legados - alicerçados, em muitos casos, na falta de autonomia política, assim como nas violências crescentes e naturalizadas (CHAUI, 2007) - ainda persistem.

Assim, optou-se por escolher alguns acontecimentos que pudessem exemplificar legados que constituem o Brasil de hoje. Assim, estas primeiras palavras ocupar-se-ão em trazer breves passagens de um Brasil autoritário. Heranças coloniais, imperiais, republicanas, ditatoriais contemporâneas.

\section{ESTADO, NAÇÃO E FUSÃO DE IDEIAS}

Talvez seja difícil dizer sobre o Brasil sem que brevemente também se fale sobre estado, nação e a junção destas ideias. Pensar o Brasil de hoje significa tentar entender esta entidade denominada estado-nação, que nem sempre existiu e que carrega as contradições de sua indeterminação (CHAUI, 1989). Assim, a nação

[...] é uma prática política e social, um conjunto de ações e de relações postas pelas falas e pelas práticas sociais, políticas e culturais para as quais ela serve de referência empírica (o [espaço territorial']), imaginária (a comunidade cultural e a unidade política por meio do Estado) e simbólica (o campo de significações culturais constituídas pelas lutas e criações social-históricas). A nação não é; ela se faz e se desfaz (CHAUI, 1989, p. 114).

Portanto, a nação é um constructo histórico que foi acoplado à formação dos estados modernos. A intenção da criação do sentimento nacional pretende inculcar nos sujeitos fidelidades correlativas ao estado. Este último - entendido como uma forma de organização do poder político, através de suas instituições de governo e sujeitos dirigentes - procura impor aos sujeitos que habitam o que consideram pretensamente como seu espaço territorial, certa unidade cultural, linguística e identitária (ROSSOLILLO, 2008).

O processo de formação do Estado-Nação é um fenômeno moderno que teve seu auge no período de 1830-1880. Embora seja um processo que tenha se iniciado na Europa, essa forma político-territorial espalhou-se pelo mundo, com tempos e processos diferenciados (CARVALHO, 2012, p. 51)

No Brasil, a formação do estado-nacional teve suas peculiaridades e seu processo histórico, desde a colonização, foi de suma importância para constituir os fundamentos de sua nacionalidade (CARVALHO, 2012).

É o próprio estado-nacional, através de seus sujeitos detentores de mais poder, que procura inventar o nacionalismo. São suas estruturas de poder que possibilitam que o projeto político de fusão de estado e nação ocorra. Esta ideia ilusória, mítica, denominada nação, acaba por cunhar nos sujeitos sentimentos de pertencimento a partir do inculcamento de unificação, em determinado espaço territorial, de língua, cultura e tradições (LEVI, 2008). Entretanto, a constituição de tal molde frequentemen- 
te associa-se a práticas históricas de brutalidade e barbárie das mais variadas. Nesses casos, quaisquer atitudes valem para manter a ordem estabelecida e as estruturas de poder vigentes.

Neste sentido, pode-se entender a nação como uma abstração, como uma comunidade política imaginada, em que sujeitos de lugares e culturas diversas, até mesmo distantes, que mantiveram pouca ou nenhuma relação entre si, acabaram por crer que viviam em comunhão no interior de um estado (ANDERSON, 2008). Isso significa dizer que foi a ideia de nação que desempenhou a função de tentar a integração dos sujeitos no interior do espaço territorial defendido pelo estado.

\section{BREVES PASSAGENS DE UM BRASIL AUTO- RITÁRIO}

Existem vários Brasis no Brasil, mas, desde seus primórdios, suas diferenças foram negadas, reprimidas e violentadas. Os territórios ${ }^{2}$, que aqui já existiam antes da colonização - nomeados, habitados, utilizados e apropriados pelos sujeitos das culturas locais - foram invadidos, explorados e expropriados pela lógica ocidental europeia. Os reduziram (ou pelos menos tentaram) a um nome: Brasil. Resignificaram usos, impuseram interesses, desenharam formas abstratas, subjugaram: nativos, índios (que não eram das Índias); e negros (que não eram autóctones). Inventaram um Brasil. Invenção autoritária, brutal.

Brasil, sociedade autoritária (CHAUI, 2007) e brutal porque não aceita ou reconhece suas diferenças. Permite-se utilizar quaisquer recursos - das violências diversas - para fazer-se apenas um. Processo histórico imbricado por relações de dominação, de subjugações diversas, de forças desiguais em que uns poucos sujeitos possuem mais poder de decisão do que outros. Caminhos impostos a se seguir. Sociedade autoritária porque violentamente inventada através da inferiorização e silenciamento da maioria dos seus habitantes.

Observa-se que muitas vezes as desigualdades entre os sujeitos do mundo são produzidas a partir da invenção de inferioridades naturais. Por outro lado, estas são justificadas pelas inúmeras diferenças entre estes sujeitos e suas culturas. Nesse sentido, a própria ideia naturalizada das desigualda- des acaba por justificar também relações desiguais, em que alguns sujeitos se sobrepõem a outros, impondo a eles suas vontades e seus interesses. Tais relações permeiam variados âmbitos da vida e se caracterizam por atitudes violentas (explícitas ou não) e pela negação da condição de sujeitos autônomos e ativos - capazes de decisão e vontade próprias - no interior das relações de uns com os outros, no e com o mundo. Assim, são instauradas e naturalizadas relações de dominação, de opressão (FREIRE, 2001a, 2001b, 2002).

Podem-se exemplificar tais relações a partir, por exemplo, das violências patriarcais ou de gênero, em que mulheres e filhos são subjugados ao patriarca da família. Outros exemplos de relações de dominação, ainda bastante percebidos na atualidade, são aqueles relativos aos preconceitos raciais, ou mesmo aos de classe (envolvendo inferiorizações associadas à cor da pele ou às hierarquias socioeconômicas).

Não se pode negar a importância do momento da fundação do Brasil como prevalência desses autoritarismos coetâneos, que extrapola datas e persiste como marca. Que se mantém vivo (ainda que com várias distinções) nas vidas e experiências dos seus sujeitos por séculos. País que, inevitavelmente, sente as agruras de pessoas que carregam em suas raízes o massacre dos homens e mulheres que aqui viviam - andando nus, com suas peles vermelhas e narizes bem feitos (CAMINHA; ARROYO, 1963) - bem antes dos colonizadores. Muitas vezes massacrados porque resistiram, porque em sua liberdade sutil, não admitiam a sua dominação por aqueles europeus. Outras vezes, massacrados porque seus corpos foram violentados: feitos escravos - gente para ser gasta no trabalho (RIBEIRO, 2008). Ou massacradas, porque mulheres feitas de ventres, progenitoras de mamelucos ${ }^{3}$, não raro, "[...] serviçais del-rei, impositores da dominação que os oprimia" (RIBEIRO, 2008, p. 97). Ou massacrados porque docilizados através das mentes catequizadas. Pessoas-objeto que tiveram suas subjetividades e culturas negadas.

Além deles, negros e negras, de etnias diversas (inclusive, não raramente rivais) trazidas do outro lado do oceano Atlântico. Mais gente coisificada para ser gasta no trabalho. Portugueses - 
desventurados em sua suposta ventura - que não entendiam que enquanto os supliciava, construíam os legados brutais de seus próprios descendentes. Produziam desumanidades. Também se desumanizavam (FREIRE, 2002; ZITKOSKI, 2008).

Nenhum [país] que passasse por isso como sua rotina de vida, através de séculos, sairia dela sem ficar marcado indelevelmente. Todos nós, [brasilianos], somos carne da carne daqueles pretos e índios supliciados. Todos nós [brasilianos] somos, por igual, a mão possessa que os supliciou. A doçura mais terna e a crueldade mais atroz aqu se conjugaram para fazer de nós a gente sentida e sofrida que somos e a gente insensível e brutal, que também somos (RIBEIRO, 2008, p. 108).

Sujeitos Brasis: autóctones, nascidos ou trazidos. Gentes-habitantes do que se denomina Brasil. Diferenças e singularidades pressionadas pelo desejo da unicidade inexistente. Miscigenação legada ou, até mesmo, forçada. Dóceis e conformados, brutalizados e transgressores. Sujeitos Brasis, hoje genericamente chamados de brasileiros: nome dado aos exploradores do pau-brasil no período colonial; portugueses que voltavam ricos à sua terra natal ${ }^{4}$.

Mito das três raças: brasilianos oriundos de índios, negros e portugueses. Generalizações étnicas: sujeitos de diversas etnias autóctones, anteriores à invasão portuguesa dos seus territórios, reduzidos todos ao nome índios. Abundantes culturas africanas - de um continente macroescalar - distintas cultural e socioespacialmente. Pessoas reduzidas todas à designação negros. Gentes-habitantes gastas no trabalho, assim como migrantes posteriormente trazidos do Oriente ou da Europa, a partir do século XIX (SCARLATO, 2005), considerados irrelevantes na miscigenação (desigual e segregacionista) dos sujeitos Brasis.

Este Brasil possui as prevalências de sua invenção brutal. Multiplicidades de culturas e gentes, de jeitos de pensar e sentir, de fazeres e práticas diversas que não foram, apesar da voracidade, totalmente engolidas pelos desejos do ocidental corpo do mundo (HISSA, 2009).

Hoje, Brasil república, herança da proclamação da lógica privada dos sujeitos hegemônicos. Discursos de res-pública (EISENBERG; POGREBINSCHI, 2008). Porque não trouxe a possibilidade efetiva de participação política à maioria de suas gentes. Porque não tornou coletivas as questões de interesse comum.
Assim, acoplada aos interesses liberais, a república do Brasil foi proclamada consagrando dominações. Mesmo com a sua proclamação e a anterior abolição da escravidão, a sociedade continuava caracterizada por suas desigualdades profundas e pela concentração do poder (CARVALHO, 2005, p. 93). Instituída a partir de interesses privados por uma pequena e parca elite - oligárquica e europeizada - desejosa apenas em estabelecer um regime que mantivesse, garantisse e favorecesse seus interesses. Perpetuou forças e poderes.

República brutal e violenta. Persistências no e do Brasil. Autoritarismos explícitos. Tempo de movimentos messiânicos (CHAUI, 2007), tradicionalismos forjados: de Canudos, Contestado e Juazeiro de Padim Ciço. De confrontos, como a Revolta da Armada e da não aceitação da obrigatoriedade das vacinas e dos princípios higienistas (CARVALHO, 2005). Resistências massacradas.

Ao longo da consolidação republicana, seus sujeitos hegemônicos possuíam e utilizaram "[...] instrumentos ideológicos e políticos para estabelecer um regime profundamente autoritário" (CARVALHO, 2005, p. 93). Autoritarismo arraigado em violências ou paternalismos do estado para com seus sujeitos. Discursos de formação de um corpo político soberano ou de igualdade de direitos, não se constituíram em práticas. Ideais que, os republicanos, ensimesmados, apregoavam. $\mathrm{O}$ que restou foram apenas ações a favor da modernização do país e da liberdade individual (jamais coletiva).

Esta liberdade, típica dos ideais modernos, era carregada da lógica privada - detinha-se acerca dos direitos de ir e vir, à propriedade, à opinião, à religião. Esta liberdade moderna constituía-se também do direito à participação política, que, contudo, era exercida quase que exclusivamente através da representação, ao invés de acontecer a partir de envolvimento direto (CARVALHO, 2005, p. 83). As diferenças foram reforçadas enquanto desigualdades, através da ideia de individualidade. Violência e autoritarismo, desigualdade e patriarcalismo, particularização do público - manutenção de heranças. República feita de antigas marcas, embasada pela lógica histórica de relações de dominação.

Brasil, corpo político desfigurado, porque au- 
sente de maiorias e respeito às diversidades. Corpo mutilado - ocidentalizado. Feito de poucas cabeças hierárquicas que relegam às gentes seus mandos e desmandos. Uma República incompleta, abissal, porque não raramente faltaram as bocas das maiorias diversas - caladas ao longo do percurso histórico do Brasil - para se pronunciarem como participantes da vida política e dizerem sobre necessidades e interesses das coletividades. Resistências brutalmente desestimuladas. A república oligárquica do Brasil consolidou-se a favor e "[...] para os grandes proprietários, os barões do café e os coronéis, com seus vastos domínios privados" (FLORES, 2008, p. 82). Legado imaginário e simbólico.

Com o chamado Estado Novo, apesar de profundas mudanças no âmbito nacional, as relações de dominação, e suas características autoritárias, persistiram (e até se aprofundaram). Com um forte apelo a uma política de massas (propagandista e midiática), o governo de Vargas parecia se esforçar em manter a ordem interna do país, em mostrar a inexistência dos conflitos sociais e em forjar a consciência nacional (CHAUI, 2007).

"No plano político, o autoritarismo, que sempre marcou presença na sociedade [brasiliana], foi reforçado nesse período" (CAPELATO, 2007 , p. 140). A própria regulamentação das leis trabalhistas pelo estado estava associada a esta intenção de passar aos sujeitos Brasis a visão de unidade nacional, ou seja, de nação cordial e pacífica.

A legislação trabalhista visava a regulamentar os conflitos entre patrões e operários e a controlar as atividades dos sindicatos até então independentes. $\mathrm{O}$ objetivo maior consistia no impedimento de que conflitos sociais se expressassem na esfera pública" (CAPELATO, 2007, p. 120).

A ideia de nação varguista não se tratava de um projeto coletivo, realizado a partir do enfrentamento dialógico das diferenças, contradições e conflitos gestados no interior de seu espaço territorial, constituído a partir de invasões, expropriações, segregações e violências das mais variadas. Pelo contrário, a coletividade apregoada pelo governo pretendia apagar as diferenças a partir da ideia de criação de uma pretensa unidade embasada na homogeneização cultural, social e identitária de seus sujeitos distintos. Aliás, ideia que perpassa os próprios intentos acerca da constituição de nações ou nacionalismos (CHAUI, 1989). Cultura e identidade nacional forjadas violentamente sobre o que, desde a gênese do Brasil, se configurou por suas diferenciações. Arestas aparadas sob pressão.

O exemplo típico e mais comum acerca do autoritarismo no Brasil é traduzido a partir de todo o período da ditadura militar, que compôs cerca de vinte e um anos de percursos repletos de violências, de relações de dominação, de desigualdades. Brutalidades institucionais arraigadas (CHAUI, 1989, 2007; MARTINS, 2011).

Desde a década de 1980, movimentos sociais, exercícios de participação, mostram-se de forma mais explícita. Dificuldades (mas também desejos) de sujeitos, Brasis, na inserção da política do país, com seus atos intencionais. Entretanto, outros autoritarismos surgem: mais sutis, menos latentes.

Estes Brasis autoritários, legados, não são difíceis de serem exemplificados. Talvez sejam até óbvios (mas, por isso, não menos importantes). Os problemas estão nas histórias não contadas, invisibilizadas, desvalorizadas: nas resistências. Não há ação que deixe de gerar ação contrária. Ininterrupta. Autoritarismos que encontram obstáculos. Resistências que esbarram em mais autoritarismos. $E$ mais resistências. Silenciadas.

As explicitações e exemplificações feitas aqui acerca de processos autoritários no Brasil não negam a existência e a importância, em vários momentos, das resistências dos seus sujeitos invisibilizados, menos poderosos. Os conflitos, inúmeros, existiram (e ainda existem) abundantemente. As formas de transgressão também. Não há como negar as inúmeras conquistas e lutas, várias vezes feitas de presenças insistentes, mesmo no interior de amplos processos e tentativas de desestímulo e desmobilização.

Talvez, na atualidade, possa-se falar de uma abertura política maior, do direito garantido à participação política e de uma democratização crescentes. Mas não se pode deixar de pensar as prevalências destas heranças autoritárias. Elas ainda persistem, insistem. Com diferenças, sutilezas. Como algo que marca corpos e suas memórias. Até mesmo como cultura. 


\section{SILÊNCIOS LEGADOS}

Cultura do silêncio (FREIRE, 2002). Um dos legados a se considerar no Brasil. Silêncio das vozes que se conformaram com seu calar, que não pronunciam seu mundo e nem dizem suas palavras. Conformismo forjado nos sujeitos de um país acostumado a negar seus conflitos ou a tratá-los de forma violenta. Mordaça, hoje no pensar-agir-sentir das pessoas, feita de memórias que acreditam que têm que se calar, porque historicamente não lhes foi permitido dizer, e, não raro, quando insistiram, suas línguas foram cortadas.

Estas marcas do silêncio permanecem. Há a carência da cultura do falar, do pronunciar, do fazer intersubjetivo. O público, no Brasil, sempre foi confundido com o privado, as relações (violentas, autoritárias) foram e continuam sendo (ainda que sob formas distintas) patriarcais, racistas, classistas. Preconceituosas. Uns poucos têm voz para pronunciar seu mundo e impor seus interesses. A maioria parece tomar para si o silêncio que lhes foi infligido. Continua subjugada às vontades arbitrárias de uns poucos possuidores de voz e poder.

Desta maneira, as relações sociais e intersubjetivas se reduzem a violentas relações de mando-obediência, em que, pretensiosamente, alguns sujeitos - considerados superiores, mais capazes (possuidores de voz) - legitimamente subjugam outros: inferiorizados, invisibilizados (SANTOS, 2006). Estas violências relacionais - ou relações de dominação — vão desde agressões físicas até violências simbólicas (CHAUI, 2007, p. 90), mais sutis e permeadas por preconceitos dos mais variados (como os de gênero, raça ou socioeconômicos).

Diversos conflitos no Brasil foram tratados com formas variadas (e inclusive apuradas) de violências. Ao longo de seu percurso histórico, geralmente foram (e ainda são) resolvidos a partir de relações de dominação. 516 anos de escravidão (legal até 1888, ilegal depois); 516 anos de latifúndio; de patriarcalismo; de encobrimentos (STRECK, 2001). Os acontecimentos no Brasil em que conflitos de origens e contextos histórico-geográficos diversos foram violentamente tratados são abundantes. Abundantes violências institucionais.

Na Colônia, índios preados e escravizados, Palmares arra- sado, Felipe dos Santos amarrado a cavalos e esquartejado, Tiradentes enforcado e esquartejado; no Império, Frei Caneca fuzilado, 30 mil mortos na Cabanagem, rosários de orelhas de cabanos no pescoço dos soldados; na República Velha, presos degolados na revolta Federalista [...], Canudos arrasada, seus prisioneiros degolados (os que se negavam a dar um Viva à República), fuzilamento sumário de rebeldes no Rio de Janeiro e em Santa Catarina durante a revolta da Armada, surra de espada nos soldados, chibata no lombo dos marinheiros [...]; no Estado Novo, na Delegacia de Ordem Política e Social, espancamento de presos políticos nos rins e na sola dos pés com canos de borracha, queimaduras com pontas de cigarro [...], assassinato; na outra ditadura, prisão, seqüestro, bofetão, espancamento [...]; na era da Constituição cidadã, Candelária, Vigário Geral, Carandiru, Eldorado, Corumbiara, Manaus, Diadema, extorsão, tortura, massacre, pena de morte sem julgamento (CARVALHO, 2005, p. 327).

Gêneses da cultura do silêncio. Os sujeitos Brasis, que em algum momento ousaram se rebelar, "[...] conhecem o peso da repressão que se abate sobre eles toda vez que contestam o estabelecido" (CHAUI, 1989, p. 80). O que impera, historicamente, é a cultura do silêncio, autoritária, desigual — feita de ausências e invisibilidades (SANTOS, 2006), da sujeição dos sujeitos.

Neste sentido, a produção de imagens e ações com o intuito de ocultar conflitos e banalizar a violência no Brasil é constantemente utilizada e revisitada ao longo de sua história. Criam-se mitos, como, por exemplo, o do povo brasiliano, cordial, pacífico e ordeiro (CHAUI, 2007), tolerante às diferenças porque gestados por miscigenações. São utilizados, comumente, mecanismos propagandistas, que difundem a ideia do país tropical, feliz e ensolarado, feito de festas e alegrias infinitas. Falase do país em desenvolvimento, uma das maiores economias do mundo, da ascensão das classes trabalhadoras, do seu aumento no consumo de bens e serviços (única felicidade contemporânea possível). Violências simbólicas, que dissimulam experiências autoritárias e desiguais.

Talvez, uma das maiores violências praticadas, seja a própria intenção de negar o conflito enquanto algo inerente aos sujeitos do mundo e suas relações. O que se tenta é evitar que os conflitos e contradições da sociedade sejam trazidos à tona para que, através da coletividade, possam ser pensados e debatidos. Seja pela violência belicosa, ou a partir da produção das ausências ou ocultamentos, o que se percebe é esta cultura do silêncio, feita de vozes que não pronunciam seu mundo (FREIRE, 2002). 


\section{4. ÚLTIMAS PALAVRAS: PARA PENSAR POSSIBI- LIDADES E ABERTURAS}

Pressupõe-se que, em uma sociedade de formação autoritária como a do Brasil, gestar lugares de encontros, mediados por relações dialógicas entre seus sujeitos, já é, em si, uma maneira de transformação socioespacial. Pensar a potência das relações dialógicas é uma tentativa de buscar alternativas à cultura do silêncio. Aos silenciamentos. Por isso a importância de estudos e pesquisas acerca desses legados autoritários.

Pensar culturas dialógicas não é, ingenuamente, professar o fim dos conflitos. As relações entre os sujeitos do mundo são indelevelmente políticas. Implicam escolhas, posicionamentos, intencionalidades. Sendo assim, a politicidade é própria dos sujeitos do mundo (FREIRE, 2002) e suas relações são, consequentemente, conflituosas.

Os lugares são espaços onde se dão experiências existenciais de sujeitos do mundo. Neles a vida e as vivências têm fortes significados. É a partir deles que os exercícios dialógicos, cotidianos, podem se construir. Da mesma forma que, neles, é que as relações autoritárias podem se dar. Quando os lugares passam a ser usados por seus sujeitos para travar diálogos acerca de interesses ou conflitos comuns, a categoria lugar deixa de ser apenas suporte de produção e reprodução da existência, do cotidiano, mergulhado na repetição (DAMIANI, 2002) e no conformismo, e passa a ser território carregado de politicidade.

No Brasil contemporâneo, é injusto dizer que não existam relações dialógicas e lugares de encontros. Mas é lícito dizer que se está longe de compor uma cultura dialógica, em que os sujeitos Brasis (em sua maioria) sejam ativos partícipes da vida coletiva. Também não é uma leitura equivocada falar que são parcos os lugares onde as pessoas possam se encontrar para dialogar sobre interesses e conflitos existentes na coletividade. Hoje, a política do Brasil vive a fragilidade de seus sujeitos e a incapacidade de trazer para a coletividade seus conflitos (BIGNOTTO, 2004, p. 39).

Entretanto, as relações autoritárias legadas pelos percursos do Brasil não encerram o país em uma história catastrófica, finalizada, com o triunfo das minorias detentoras de mais poder. Há poder também no fazer e no pensar cotidianos, das pesso- as que vivem suas existências nos lugares do mundo. Este poder pode reproduzir conformadamente as relações autoritárias, que segregam e violentam as gentes de maneiras tão diversas, mas, por outro lado, pode igualmente ser resistência e possibilidade. História e devir são indissociáveis.

A transformação pode ser plasmada nos lugares, a partir do poder dos sujeitos, ativos e reflexivos, de fazer germinar outras relações: mais humanas, menos violentas, dialógicas. Os sujeitos dos lugares - hoje cada vez mais acoplados ao mundo - são, assim, aqueles que também detêm certa parcela de poder para escrever seus caminhos e descaminhos a partir de escolhas autônomas e conjuntas.

A dominação impõe vontades e subjuga gentes a vontades individualistas - desumaniza. Por outro lado, resistir à dominação é uma possibilidade de construção coletiva de humanização dos homens e mulheres do mundo, gestada através da autonomia (FREIRE, 2001).

Os lugares do mundo também têm suas limitações, em geral, exteriores. Lógicas externas, hegemônicas, muitas vezes caracterizadas pelo autoritarismo e repletas de relações de dominação, chegam aos lugares impondo suas vontades e desmandos. Mas estas não podem ser consideradas como fechamentos absolutos. Os lugares, quando feitos de encontros, são carregados de pensamentos e ações utópicas, de aberturas, de poder de resistência. Hoje, lugar e mundo se conjugam numa correlação de forças intensa entre manutenção e transformação.

Por isto, o Brasil brutal, espaço territorial feito de relações de dominação, não pode ser pensado longe do seu contato com o mundo. Sua invenção e seus legados estão amplamente ligados ao corpo do mundo ocidentalizado (HISSA, 2009). Aos processos de dominação longínquos, de lugares distantes que, paulatinamente, foram difundidos e impostos a tantos outros lugares. Em contraparti$\mathrm{da}$, pode ser pensado e feito de outras maneiras. Se existem vários Brasis no Brasil, neste também existem vários lugares de possíveis encontros. Se a história do país é marcada de autoritarismo e dominação - fechamentos herdados - isso não exclui que nele existam e sejam gestadas resistências. Culturas dialógicas, caracterizadas por gentes ativas em seus espaços vividos. Aberturas possíveis manifestadas 
nos lugares e potencializadas pelos encontros.

Lugares de encontros possíveis e de possibilidades abertas. De resistência às relações de dominação e de construção de culturas dialógicas. Territórios contra a cultura do silêncio, autoritária, feita de violências e de heranças vergonhosas. A favor do respeito às diferenças, da feitura de bens comuns e da vontade de tratar os conflitos e contradições através do diálogo e da consequente humanização dos seus sujeitos. Lugares de utopias, de possibilidades, de aberturas, de resistências, de exercícios do poder e da ação e reflexão política coletiva. Territórios de libertação, de resistências aos autoritarismos legados. Resta uma boa questão: como e onde gesta-los?

\section{REFERÊNCIAS BIBLIOGRÁFICAS}

ANDERSON, Benedict R. O'G. Comunidades imaginadas: reflexões sobre a origem e a difusão do nacionalismo. São Paulo: Companhia das Letras, 2008.

BIGNOTTO, Newton. Problemas atuais da teoria republicana. In: CARDOSO, Sérgio. Retorno ao republicanismo. Belo Horizonte: Editora UFMG, 2004. p. 17-43.

CAMINHA, Pero Vaz de; ARROYO, Leonardo. Carta a El-Rei D. Manuel. São Paulo: Dominus, 1963.

CAPELATO, Maria Helena. O Estado Novo: o que trouxe de novo? In: FERREIRA, Jorge; DELGADO, Lucilia de Almeida N. (Orgs.). O Brasil Republicano; o tempo do nacional-estatismo: do início da década de 1930 ao apogeu do Estado Novo. 2. ed. Rio de Janeiro: Civilização Brasileira, vol. 2, 2007. p. 107-143.

CARVALHO, José Murilo de. Pontos e Bordados; escritos de história e política. 2. reimpr. Belo Horizonte: Editora UFMG, 2005.

CARVALHO, Naiemer Ribeiro de. Geographia do Brazil: a construção da nação nos livros didáticos de geografia da Primeira República. 2012. 209 f. Dissertação (Mestrado em Geografia) - Departamento de Geografia, Instituto de Geociências, Universidade Federal de Minas Gerais, Belo Horizonte, 2012.

CHAUI, Marilena. Conformismo e resistência; aspectos da cultura popular no Brasil. 4. ed. São
Paulo: Brasiliense, 1989.

CHAUI, Marilena. Brasil: mito fundador e sociedade autoritária. São Paulo: Fundação Perseu Abramo, 2007.

DAMIANI, Amélia Luisa. O lugar e a produção do cotidiano. In: CARLOS, Ana Fani Alessandri (Org.). Novos caminhos da geografia. São Paulo: Contexto, 2002. p. 161-172.

EISENBERG, José; POGREBINSCHI, Thamy. Onde está a democracia? 1. reimpr. Belo Horizonte: Editora UFMG, 2008.

FLORES, Elio Chaves. A consolidação da República: rebeliões de ordem e progresso. In: FERREIRA, Jorge; DELGADO, Lucilia de Almeida N. (Orgs.). O Brasil Republicano; o tempo do liberalismo excludente: da proclamação da República à revolução de 1930. 3. ed. Rio de Janeiro: Civilização Brasileira, vol. 1, 2008. p. 45-88.

FREIRE, Paulo. A importância do ato de ler: em três artigos que se completam. 26. ed. São Paulo: Cortez/ Autores Associados, 1991.

FREIRE, Paulo. Ação cultural para a liberdade e outros escritos. 9. ed. São Paulo: Paz e Terra, 2001.

FREIRE, Paulo. Pedagogia da autonomia; saberes necessários à prática educativa. 18. ed. São Paulo: Paz e Terra, 2001 a.

FREIRE, Paulo. Pedagogia da Esperança; um reencontro com a Pedagogia do Oprimido. 8. ed. São Paulo: Paz e Terra, 2001b.

FREIRE, Paulo. Pedagogia do Oprimido. 34. ed. Rio de Janeiro: Paz e Terra, 2002.

HAESBAERT, Rogério. Concepções de território para entender a desterritorialização. In: SANTOS, Milton [et. al.]. Território, territórios: ensaios sobre o ordenamento territorial. 3. ed. Rio de Janeiro: Lamparina, 2007. p. 43-71.

HISSA, Cássio Eduardo Viana. Territórios de diálogos possíveis. In: RIBEIRO, Maria T. F.; MILANI, Carlos R. S. (Orgs.). Compreendendo a complexidade socioespacial contemporânea: o território como categoria de 
diálogo interdisciplinar. Salvador: EDUFBA, 2009. p. 36-84.

LEVI, Lucio. Nacionalismo. In: BOBBIO, Norberto; MATTEUCCI, Nicola; PASQUINO, Gianfranco. Dicionário de política. 13. ed. Brasília: Ed. Universidade de Brasília, vol. 2, 2008. p. 799-806.

MARTINS, José de Souza. A política do Brasil; lúmpen e místico. São Paulo: Contexto, 2011.

PORTO-GONÇALVES, Carlos Walter. Quem nasce no Brasil é o que mesmo? Carta Maior, 16 jun. 2008. Análise \& Opinião. Disponível em: <http://www.cartamaior.com.br/templates/analiseMostrar.cfm?coluna_id=3912>. Acesso em: 27 nov. 2010.

RIBEIRO, Darcy. O povo brasileiro: a formação e o sentido do Brasil. São Paulo: Companhia das Letras, 2008.

ROSSOLILLO, Francesco. Nação. In: BOBBIO, Norberto; MATTEUCCI, Nicola; PASQUINO, Gianfranco. $\mathrm{Di}$ cionário de política. 13. ed. Brasília: Ed. Universidade de Brasília, vol. 2, 2008. p. 795-799.

SANTOS, Boaventura de Sousa. Para uma sociologia das ausências e uma sociologia das emergências. In: SANTOS, Boaventura de Sousa (Org.). Conhecimento prudente para uma vida decente: um discurso sobre as ciências revisitado. 2. ed. São Paulo: Cortez, 2006. p. 777-821.

SANTOS, Milton. Da totalidade ao lugar. 1. ed. 1. reimpr. São Paulo: Edusp, 2008.

SANTOS, Milton; SILVEIRA, Maria Laura. O Brasil: território e sociedade no início do século XXI. 13. ed. Rio de Janeiro: Record, 2010.

STRECK, Danilo R. Uma pedagogia do (outro) descobrimento. In: FREIRE, Ana Maria Araújo (Org.). A pedagogia da libertação em Paulo Freire. São Paulo: Editora Unesp, 2001. p. 51-56.

ZITKOSKI, Jaime José. Humanização/desumanização. In: STRECK, Danilo R.; REDIN, Euclides; ZITKOSKI, Jaime José. (Orgs.). Dicionário Paulo Freire. Belo Horizonte: Autêntica, 2008. p. 214-216.

\section{Notas de Fim:}

1- A noção de espaço territorial está relacionada ao espaço delimitado, necessariamente associado a um estado, mesmo que este possua outras nações, culturas, etnias em seu interior. Nesse sentido, o espaço territorial de um estado pode ser constituído de diversidades internas, como no caso do Brasil, e, apesar de uma suposta unidade territorial existente, o que se pode observar são inúmeras diferenças. Espaços territoriais podem ser constituídos de territórios variados, pensando-se que o conceito de território extrapola os limites de um estado (SANTOS; SILVEIRA, 2010).

2- Quando se fala de território, neste estudo, pretende-se pensá-lo como um conceito amplo, híbrido. Um constructo histórico, compreendido a partir das diversas relações socioespaciais que, necessariamente, envolvem relações de poder. Nesse sentido, o território pode ser compreendido como valor ético, simbólico e vivencial dos sujeitos que nele habitam ou se relacionam. Que dele se utilizam e nele se organizam para produzir não somente sua existência, como, também, suas identidades, seus modos de vida, sentidos e significações. Uma acepção que além de necessariamente econômica e política, também é a expressão de um processo social, cultural (SANTOS, 2008; HAESBAERT, 2007; HISSA, 2009).

3- Mamelucos ou brasilíndios: primeiros mestiços nascidos no Brasil, "gerados por pais brancos, a maioria deles lusitanos, sobre mulheres índias [...]" (RIBEIRO, 2008, p. 95).

4- "O sufixo eiro [...] tem, entre outras funções, a de assinalar uma ação ou uma função como em madeireiro, mineiro, pistoleiro, grileiro ou garimpeiro. Todavia, o adjetivo pátrio brasileiro indica a origem colonial dos que aqui chegavam e o que vinham fazer aqui. [...] É interessante observar que embora a língua portuguesa nos ofereça sinônimos para brasileiro, como brasiliense, brasilense e brasiliano essas variantes são desprezadas. [...] Brasileiro tem sido exatamente isso: aquele que vive de explorar o Brasil. Não é natural ser brasileiro. É uma opção." (PORTO-GONÇALVES, 2008).

\section{Correspondência da autora:}

Danielle Gregole Colucci e-mail: danicolucci@yahoo.com.br

Artigo recebido em: 18/01/2016

Aceito para publicação em: 16/04/2016 